\title{
Thermal and mechanical properties of polystyrene modified with esters derivatives of 3-phenylprop-2-en-1-ol
}

\author{
Marta Worzakowska
}

Received: 14 September 2014/ Accepted: 6 February 2015/Published online: 3 March 2015

(C) The Author(s) 2015. This article is published with open access at Springerlink.com

\begin{abstract}
The thermal and mechanical properties of polystyrene (PS) modified with esters derivatives of 3-phenylprop-2-en-1-ol were investigated. The influence of the content of esters on the glass transition temperature, dynamic mechanical properties, flexural properties, hardness and thermal stability of PS has been examined. It was found that the PS/ester compositions were characterized by lower stiffness, lower values of $T_{\mathrm{g}}$, lower hardness, lower stress at break, lower thermal stability and higher values of tg delta height and strain at break as compared to pure PS. The obtained results proved that esters derivatives of 3-phenylprop-2-en-1-ol can find their place as an environmentally friendly, external plasticizers of PS.
\end{abstract}

Keywords Polystyrene - Thermal properties .

Viscoelastic properties · Flexural properties · Hardness · Plasticizers

\section{Introduction}

Polystyrene (PS) is considered to be the most durable thermoplastic polymer. It is used in a wide range of products due to its versatile properties. Polystyrene is characterized by the resistance to biodegradation, stiffness or flexibility (with plasticizers), light weight, good optical, chemical and insulation properties and facile synthesis. It is

M. Worzakowska $(\square)$

Department of Polymer Chemistry, Faculty of Chemistry, Maria

Curie-Skłodowska University, Gliniana 33 Street,

20-614 Lublin, Poland

e-mail: marta.worzakowska@ poczta.umcs.lublin.pl utilized as plastics, latex paints, coating, synthetic rubbers and styrene alkyd coatings, for food-contact packing polymers, in electronics and building materials, as material for the formation of toys, cups, office supplies, etc. [1-3]. On the contrary, styrene easily copolymerizes with different monomers such as acrylonitrile, methacrylamide, divinylbenzene, butadiene, maleic anhydride, vinyl chloride, esters of organic acids, e.g., acrylates or methacrylates, unsaturated polyesters or others creating polymeric materials with unique properties suitable for many industrial applications [4-14].

In order to improve the processing, performance and elasticity of plastic materials, the polar and non-polar additives (plasticizers) are added. The interactions of plasticizer molecules with polymer chains cause disruption of the secondary valence bonds or van der Waals force between polymer molecules. As a consequence, a decrease in the intermolecular interactions and thus an increase the mobility of the polymer chains are observed. As a result, the materials are characterized by lower moduli, stiffness, glass transition temperature and hardness. Meanwhile, the ability of materials for elongation and polymer chain flexibility significantly increase [15-17]. The most, generally applied plasticizers are low molecular mass organic compounds, which are characterized by low volatility in order to prevent their rapid evaporation from manufactured products. Among commercially applied plasticizers for PS, phthalate esters such as dimethyl, diethyl, dipropyl, dibutyl, diheptyl, dioctyl, diisodecyl or benzylbutyl phthalates are the most commonly used [18-21]. In addition, the application of adipate and glutarate esters as plasticizers for the expanded PS and the liquid paraffin and zinc stearate as an internal plasticizers is reported [22, 23]. However, most of phthalates have toxic properties for human. Due to this, the intensive studies on the new, non-toxic and biodegradable materials that could 
replace harmful plasticizers are developed [24, 25]. In recent years, the utilization of eco-friendly plasticizers such as epoxidized vegetable oils, biodiesel oils, hydrogenated Castrol oil, citrate esters, poly(ethylene glycol) of low molecular weight or core-hydrogenated phthalates has been investigated [26-30].

The main objective of this paper is to study the thermal and mechanical properties of PS modified with esters derivatives of 3-phenylprop-2-en-1-ol. This alcohol occurs in nature in many oils and balsams such as cassia, styrax, hyacinth oils or Peru and Honduras balsams [31]. The esters of 3-phenylprop-2-en-1-ol are aromaticaliphatic compounds, which differ in their structure and thus in their properties. The ester of 3-phenylprop-2-en1-ol and succinic anhydride (CBE) contains two methylene groups $\left(-\mathrm{CH}_{2}-\right)$, but the ester of 3-phenylprop-2-en1-ol and sebacic acid (CSE) contains eight methylene groups $\left(-\mathrm{CH}_{2}-\right)$ in their chain spacer. $\mathrm{CBE}$ is a liquid with boiling temperature of $210{ }^{\circ} \mathrm{C}$; however, CSE is a solid with melting and boiling temperatures of 92 and $260{ }^{\circ} \mathrm{C}$, respectively. It is worth noting that those esters have high thermal stability and thus low volatility. The thermal decomposition of CBE starts about $220^{\circ} \mathrm{C}$. However, the beginning of the thermal decomposition of CSE is visible at $270^{\circ} \mathrm{C}$. CBE and CSE are slowly hydrolyzable, well-soluble compounds in organic solvents and well miscible with thermoplastic polymers [32]. Due to their properties, they can find their place as potential, eco-friendly plasticizers for specific applications, especially in the areas where humans have a direct contact, e.g., for the production of toys, medical products and food packing. In order to check their action on the thermal and mechanical properties of chosen, commercially used thermoplastic polymer such as bulk PS, the compositions containing different ester content are prepared. PS and esters were mixed together making the compositions containing from 0.5 to 20 mass $\%$ of ester. The influence of the content of esters and the structure of esters on the glass transition temperature, storage modulus, Young modulus, stress and strain at break, hardness and thermal stability of prepared materials has been evaluated and discussed.

\section{Experimental}

\section{Materials}

Esters derivatives of 3-phenylprop-2-en-1-ol were prepared through catalyzed esterification process of 3-phenylprop-2en-1-ol (98\%, Fluka) and acidic reagents such as succinic anhydride (99\%, Merck) or sebacic acid (98\%, Merck) according to the method described in Ref. [32]. The structure of esters is shown in Scheme 1. The following abbreviations for esters were used as follows: CBE (ester of 3-phenylprop-2-en-1-ol and succinic anhydride) and CSE (ester of 3-phenylprop-2-en-1-ol and sebacic acid). Polystyrene was obtained by free-radical polymerization of styrene (POCh, Gliwice, Poland) in the presence of benzoyl peroxide (1.0 mass\%) as an initiator (POCh Gliwice, Poland). The reaction was carried out at $60{ }^{\circ} \mathrm{C}$. Raw PS was washed with methanol in order to remove un-reacted monomer and benzoyl peroxide. After filtration, bulk PS was dried to a constant mass. The obtained bulk PS was characterized by SEC method. The average molecular mass and a polydispersity of prepared, bulk PS were 105, 000 and 2.7 , respectively.

\section{Sample preparation}

The PS/ester compositions were prepared by solution blending. Polystyrene was dissolved in hot chloroform, and then suitable amounts of esters were added. The solutions were precisely mixed. The obtained blends were deposited and spread over glass plate. The samples were kept for 5 days at room temperature and then at $60{ }^{\circ} \mathrm{C}$ under vacuum for 2 days in order to evaporate the solvent. The compositions contain from 0.5 to 20 mass\% of esters were prepared. In addition, samples of pure PS were also manufactured to compare the results.

\section{Methods}

Differential scanning calorimetry analysis (DSC) was carried out with a DSC 204 calorimeter, Netzsch (Germany).
Scheme 1 Structure of esters, where $\mathrm{CBE}$ is ester of 3-phenylprop-2-en-1-ol and succinic anhydride, CSE is ester of 3-phenylprop-2-en-1-ol and sebacic acid

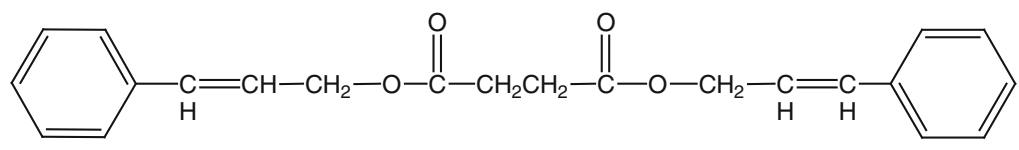

CBE

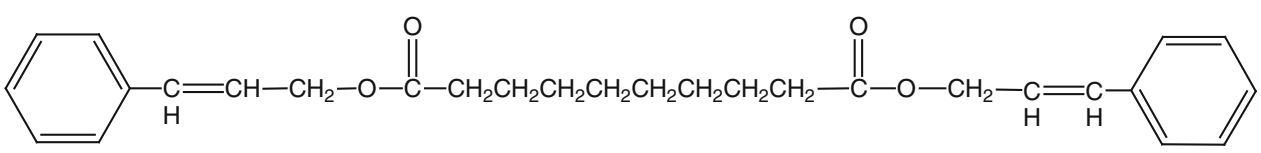

CSE 
All DSC measurements were carried out in aluminum pans with pierced lid. As a reference empty aluminum crucible was applied. The mass of the sample was about $10 \mathrm{mg}$. The dynamic scans were performed at a heating rate of $10{ }^{\circ} \mathrm{C} \mathrm{min}{ }^{-1}$ from 20 to $500{ }^{\circ} \mathrm{C}$ under argon atmosphere $\left(20 \mathrm{~mL} \mathrm{~min}^{-1}\right)$.

Dynamic mechanical analysis (DMA) was performed on a DMA Q 800 TA Instruments (USA). Tests were conducted with a double Cantilever device with a support span of $35 \mathrm{~mm}$. Measurements for all samples were made from room temperature up to temperature until the sample become too soft to be tested. A constant heating rate of $6{ }^{\circ} \mathrm{C} \mathrm{min}-1$ and an oscillation frequency of $10 \mathrm{~Hz}$ were applied. The rectangular profiles of 10-mm-wide and 2-mm-thick samples were used. The storage modulus $\left(E_{20}{ }^{\circ} \mathrm{C}, E_{30}{ }^{\circ} \mathrm{C}\right)$, loss modulus $\left(E^{\prime \prime}\right)$, tg delta maximum and tg delta height were evaluated.

Tensile properties were determined using a Zwick Roell Z010 testing machine (Germany). The specimen dimensions were $10 \mathrm{~mm}$ wide and $2 \mathrm{~mm}$ thick. The measurements were carried out at room temperature with the crosshead speed of $2 \mathrm{~mm} \mathrm{~min}^{-1}$. Young modulus, stress at break and strain at break were determined.

Hardness according to Brinell (HK) was evaluated by means of a hardness tester HPK and calculated based on following equation: $\mathrm{HK}[\mathrm{MPa}]=\mathrm{F}_{1} * 0.098066$, where $\mathrm{F}_{1}$ is a strength of pressure under definite load.

Thermal analysis (TG) was carried out on an STA 449 Jupiter F1, Netzsch (Germany) equipped with a sensor thermocouple-type $\mathrm{S}$ TG-DSC. All measurements were made in $\mathrm{Al}_{2} \mathrm{O}_{3}$ crucibles. As a reference empty $\mathrm{Al}_{2} \mathrm{O}_{3}$ crucible was applied. Dynamic scans were performed at a heating rate of $10{ }^{\circ} \mathrm{C} \mathrm{min}^{-1}$ from 40 to $700{ }^{\circ} \mathrm{C}$ under helium and air atmospheres $\left(25 \mathrm{~mL} \mathrm{~min}^{-1}\right)$. The sample mass was about $10 \mathrm{mg}$.

The gas composition evolved during heating of studied materials was detected and analyzed by a FTIR spectrometer Brucker TGA 585 (Germany) coupled on-line to STA instrument. The FTIR spectra were collected in the spectral range from 600 to $4000 \mathrm{~cm}^{-1}$ with a resolution of $4 \mathrm{~cm}^{-1}$ and 16 scans per spectrum.

\section{Results and discussion}

The DSC data are placed in Tables 1 and 2. Based on the presented results, it is clearly visible that the glass transition temperature $\left(T_{\mathrm{g}}\right)$ for pure PS is $96{ }^{\circ} \mathrm{C}$ and it is in agreement with the reported values [33, 34]. It can be also observed that with increasing the amount of added ester from 0.5 to 10 mass $\%$, the $T_{\mathrm{g}}$ values of obtained materials slightly decrease. However, when the amount of esters is higher than $10 \%$, the changes in $T_{g}$ values become more
Table 1 DSC data of PS/CBE compositions

\begin{tabular}{llcl}
\hline CBE content $/ \%$ & $T_{\mathrm{g}} /{ }^{\circ} \mathrm{C}$ & $T_{\max 1} /{ }^{\circ} \mathrm{C}$ & $T_{\max 2} /{ }^{\circ} \mathrm{C}$ \\
\hline 0 & 96 & - & 425 \\
0.5 & 96 & - & 423 \\
1 & 96 & 234 & 421 \\
3 & 92 & 230 & 419 \\
5 & 90 & 242 & 420 \\
10 & 89 & 233 & 417 \\
20 & 65 & 256 & 416 \\
\hline
\end{tabular}

Table 2 DSC data of PS/CSE compositions

\begin{tabular}{llcl}
\hline CSE content $/ \%$ & $T_{\mathrm{g}} /{ }^{\circ} \mathrm{C}$ & $T_{\max 1} /{ }^{\circ} \mathrm{C}$ & $T_{\max 2} /{ }^{\circ} \mathrm{C}$ \\
\hline 0 & 96 & - & 425 \\
0.5 & 95 & - & 420 \\
1 & 94 & 230 & 418 \\
3 & 90 & 231 & 415 \\
5 & 92 & 234 & 414 \\
10 & 87 & 238 & 413 \\
20 & 60 & 240 & 410 \\
\hline
\end{tabular}
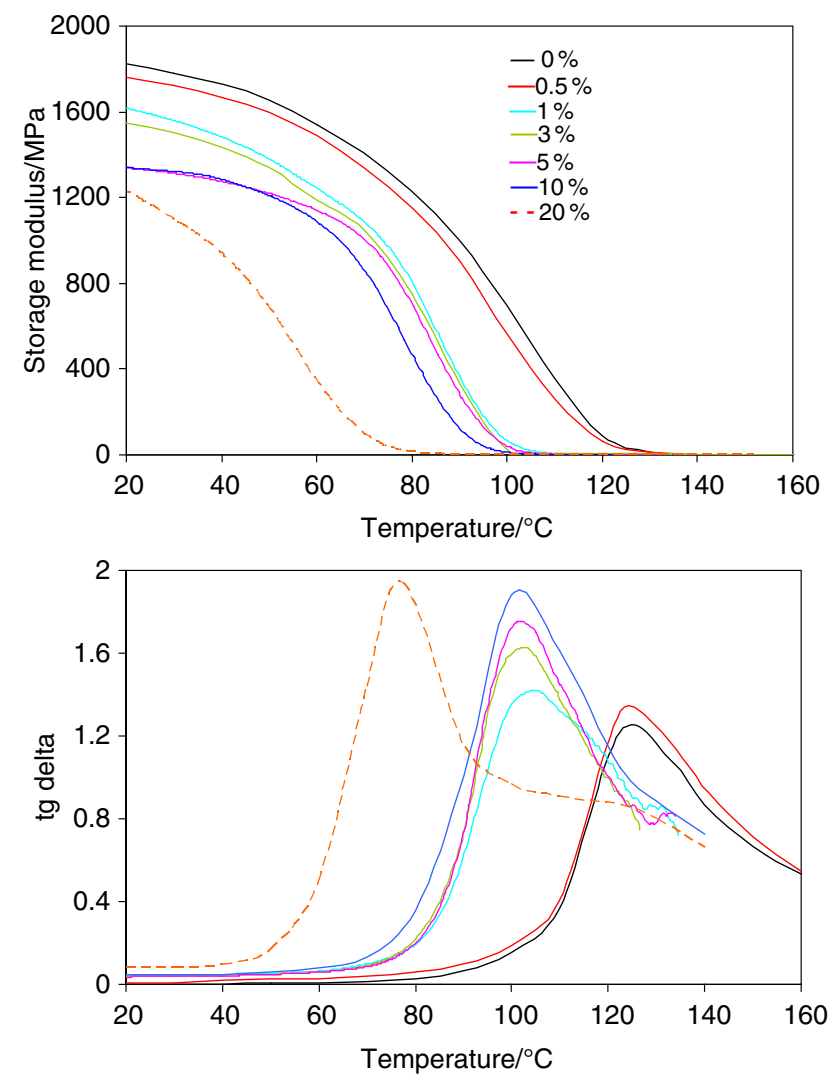

Fig. 1 Storage modulus and tg delta versus temperature for PS and PS/CBE compositions 
significant. The $T_{g}$ values are $65{ }^{\circ} \mathrm{C}$ for the PS/20 mass $\%$ $\mathrm{CBE}$ and $60{ }^{\circ} \mathrm{C}$ for the $\mathrm{PS} / 20$ mass $\% \mathrm{CSE}$. In addition, as can be seen from Tables 1 and 2, only small differences in
$T_{\mathrm{g}}$ values between the PS/lower chain-length ester (CBE) compositions and the PS/higher chain-length ester (CSE) compositions are observed. Generally, DSC curves of all

Table 3 DMA data and HK values of PS/CBE compositions

\begin{tabular}{|c|c|c|c|c|c|c|}
\hline CBE content $/ \%$ & $E_{20^{\circ} \mathrm{C}}^{\prime} / \mathrm{MPa}$ & $E_{30^{\circ} \mathrm{C}}^{\prime} / \mathrm{MPa}$ & $\operatorname{tg}$ delta $/{ }^{\circ} \mathrm{C}$ & $E^{\prime \prime} /{ }^{\circ} \mathrm{C}$ & tg delta & $\mathrm{HK} / \mathrm{MPa}$ \\
\hline 0 & 1825 & 1780 & 132 & 99 & 1.05 & 143 \\
\hline 0.5 & 1760 & 1730 & 123 & 99 & 1.32 & 130 \\
\hline 1 & 1620 & 1560 & 106 & 88 & 1.42 & 130 \\
\hline 3 & 1550 & 1510 & 104 & 88 & 1.62 & 129 \\
\hline 5 & 1440 & 1320 & 104 & 85 & 1.73 & 128 \\
\hline 10 & 1440 & 1320 & 102 & 81 & 1.88 & 123 \\
\hline 20 & 1225 & 1090 & 77 & 61 & 1.94 & 98 \\
\hline
\end{tabular}

Where HK hardness according to Brinell

Table 4 DMA data and HK values of PS/CSE compositions

\begin{tabular}{|c|c|c|c|c|c|c|}
\hline CSE content $/ \%$ & $E_{20^{\circ} \mathrm{C}}^{\prime} / \mathrm{MPa}$ & $E_{30^{\circ} \mathrm{C}}^{\prime} / \mathrm{MPa}$ & $\operatorname{tg}$ delta $/{ }^{\circ} \mathrm{C}$ & $E^{\prime \prime} /{ }^{\circ} \mathrm{C}$ & tg delta & $\mathrm{HK} / \mathrm{MPa}$ \\
\hline 0 & 1825 & 1780 & 132 & 99 & 1.05 & 143 \\
\hline 0.5 & 1650 & 1630 & 118 & 99 & 1.42 & 130 \\
\hline 1 & 1520 & 1430 & 98 & 85 & 1.53 & 128 \\
\hline 3 & 1435 & 1390 & 97 & 85 & 1.77 & 127 \\
\hline 5 & 1310 & 1265 & 96 & 83 & 1.85 & 127 \\
\hline 10 & 1280 & 1210 & 95 & 78 & 1.93 & 120 \\
\hline 20 & 1050 & 1005 & 65 & 57 & 2.15 & 85 \\
\hline
\end{tabular}

Where HK hardness according to Brinell

Table 5 Mechanical properties of PS/CBE compositions

\begin{tabular}{llll}
\hline CBE content/\% & Young modulus/MPa & Stress at break/MPa & Strain at break/\% \\
\hline 0 & 1950 & 35 & 3.2 \\
0.5 & 1870 & 35 & 3.2 \\
1 & 1800 & 33 & 3.3 \\
3 & 1740 & 30 & 3.6 \\
5 & 1650 & 28 & 3.6 \\
10 & 1590 & 25 & 4.0 \\
20 & 1350 & 20 & 5.9 \\
\hline
\end{tabular}

Table 6 Mechanical properties of PS/CSE compositions

\begin{tabular}{llll}
\hline CSE content/\% & Young modulus/MPa & Stress at break/MPa & Strain at break/\% \\
\hline 0 & 1950 & 35 & 3.2 \\
0.5 & 1890 & 33 & 3.3 \\
1 & 1850 & 30 & 3.5 \\
3 & 1770 & 30 & 3.7 \\
5 & 1680 & 26 & 3.9 \\
10 & 1620 & 23 & 4.3 \\
20 & 1390 & 18 & 6.5 \\
\hline
\end{tabular}



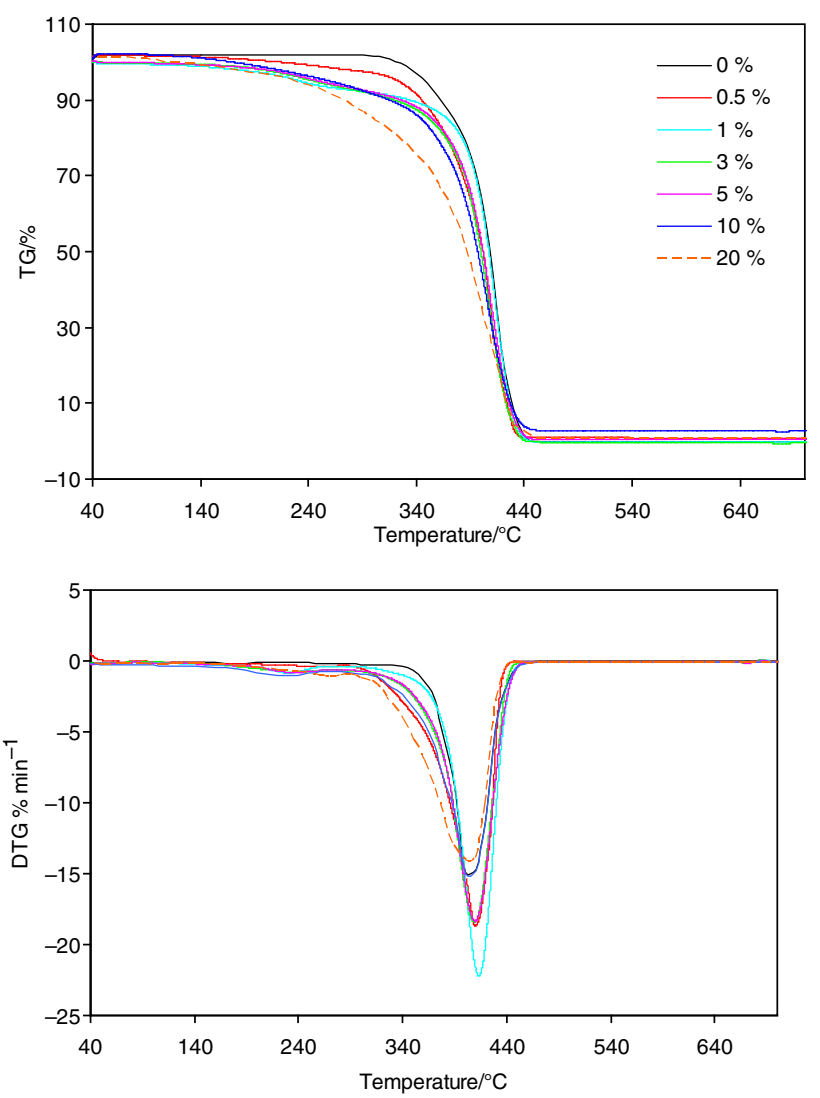

Fig. 2 TG and DTG curves of PS and PS/CBE compositions in inert atmosphere studied materials show one, asymmetric, non-well separated endothermic signal with one or two maxima ( $T_{\max 1}$ and $T_{\max 2}$ ), which is directly connected with the decomposition of the studied materials [35-37]. In addition, the presented data suggest that the characteristic decomposition temperatures are almost independent on the content of esters in the PS compositions.

In Fig. 1, the storage modulus and tg delta in the function of temperature for the obtained materials are presented. It can be seen that the major changes in storage modulus values when the materials pass through glassy state to rubbery state are observed. The storage modulus of pure PS appointed at $20{ }^{\circ} \mathrm{C}\left(E_{20}{ }^{\circ} \mathrm{C}\right)$ is $1825 \mathrm{MPa}$. However, the storage modulus for the PS/esters compositions ranges from 1050 up to $1760 \mathrm{MPa}$, as shown in Tables 3 and 4. It means that PS/ester compositions are characterized by lower stiffness as compared to pure PS. In addition, the same trend is observed for glass transition temperature (marked from DSC and DMA analyses) of prepared materials. The glass transition temperature $\left(T_{\mathrm{g}}\right)$ ( $\alpha$ relaxation) was qualified as the maximum of loss modulus (onset glass transition temperature) and as the maximum of peak of $\mathrm{tg}$ delta (midpoint glass transition temperature) [38]. DMA plots show that $T_{\mathrm{g}}$ values decrease with the increase in the amount of ester in the compositions. The same trend was observed for $T_{\mathrm{g}}$ values marked from DSC curves. It is worth noting that $T_{\mathrm{g}}$ values appointed as the maximum of

Table 7 TG and DTG data of PS/CBE compositions in inert atmosphere

\begin{tabular}{|c|c|c|c|c|c|c|c|}
\hline CBE content $/ \%$ & First mass loss $/ \%$ & $\mathrm{IDT}_{1} /{ }^{\circ} \mathrm{C}$ & $T_{\max 1} /{ }^{\circ} \mathrm{C}$ & $\mathrm{FDT}_{1} /{ }^{\circ} \mathrm{C}$ & Second mass loss $/ \%$ & $T_{\max 2} /{ }^{\circ} \mathrm{C}$ & $\mathrm{FDT}_{2} /{ }^{\circ} \mathrm{C}$ \\
\hline 0 & - & 325 & - & - & 100 & 412 & 426 \\
\hline 0.5 & - & 323 & - & - & 100 & 410 & 426 \\
\hline 1.0 & 7.6 & 230 & 231 & 250 & 92.4 & 413 & 429 \\
\hline 3.0 & 7.9 & 240 & 237 & 251 & 92.1 & 409 & 427 \\
\hline 5.0 & 8.2 & 242 & 235 & 245 & 91.8 & 410 & 429 \\
\hline 10.0 & 11.2 & 250 & 242 & 255 & 88.8 & 405 & 428 \\
\hline 20.0 & 19.8 & 203 & 272 & 287 & 84.2 & 401 & 423 \\
\hline
\end{tabular}

$I D T$ initial decomposition temperature (expressed as the temperature where $5 \%$ of mass loss is observed); FDT final decomposition temperature

Table 8 TG and DTG data of PS/CSE compositions in inert atmosphere

\begin{tabular}{|c|c|c|c|c|c|c|c|}
\hline CSE content $/ \%$ & First mass loss $/ \%$ & $\mathrm{IDT}_{1} /{ }^{\circ} \mathrm{C}$ & $T_{\max 1}{ }^{\circ} \mathrm{C}$ & $\mathrm{FDT}_{1} /{ }^{\circ} \mathrm{C}$ & Second mass loss $/ \%$ & $T_{\max 2} /{ }^{\circ} \mathrm{C}$ & $\mathrm{FDT}_{2} /{ }^{\circ} \mathrm{C}$ \\
\hline 0 & - & 325 & - & - & 100 & 412 & 426 \\
\hline 0.5 & - & 320 & - & - & 100 & 412 & 426 \\
\hline 1.0 & 7.0 & 230 & 235 & 255 & 93.0 & 410 & 430 \\
\hline 3.0 & 7.5 & 243 & 239 & 257 & 92.5 & 407 & 432 \\
\hline 5.0 & 8.0 & 245 & 235 & 243 & 92.0 & 406 & 430 \\
\hline 10.0 & 10.7 & 225 & 236 & 248 & 89.3 & 403 & 425 \\
\hline 20.0 & 20.5 & 200 & 245 & 267 & 83.2 & 400 & 420 \\
\hline
\end{tabular}

$I D T$ initial decomposition temperature (expressed as the temperature where $5 \%$ of mass loss is observed); FDT final decomposition temperature 
$E^{\prime \prime}$ are in accordance with $T_{\mathrm{g}}$ values evaluated based on a DSC analysis. It can be observed from Fig. 1 that the tg delta height that is attributed to the mobility of the resin molecules [39-42] increases as the content of ester is increased in the compositions. It testifies to higher elasticity of the PS/ester compositions than pure PS. In addition, the PS/CSE compositions exhibit lower values of storage
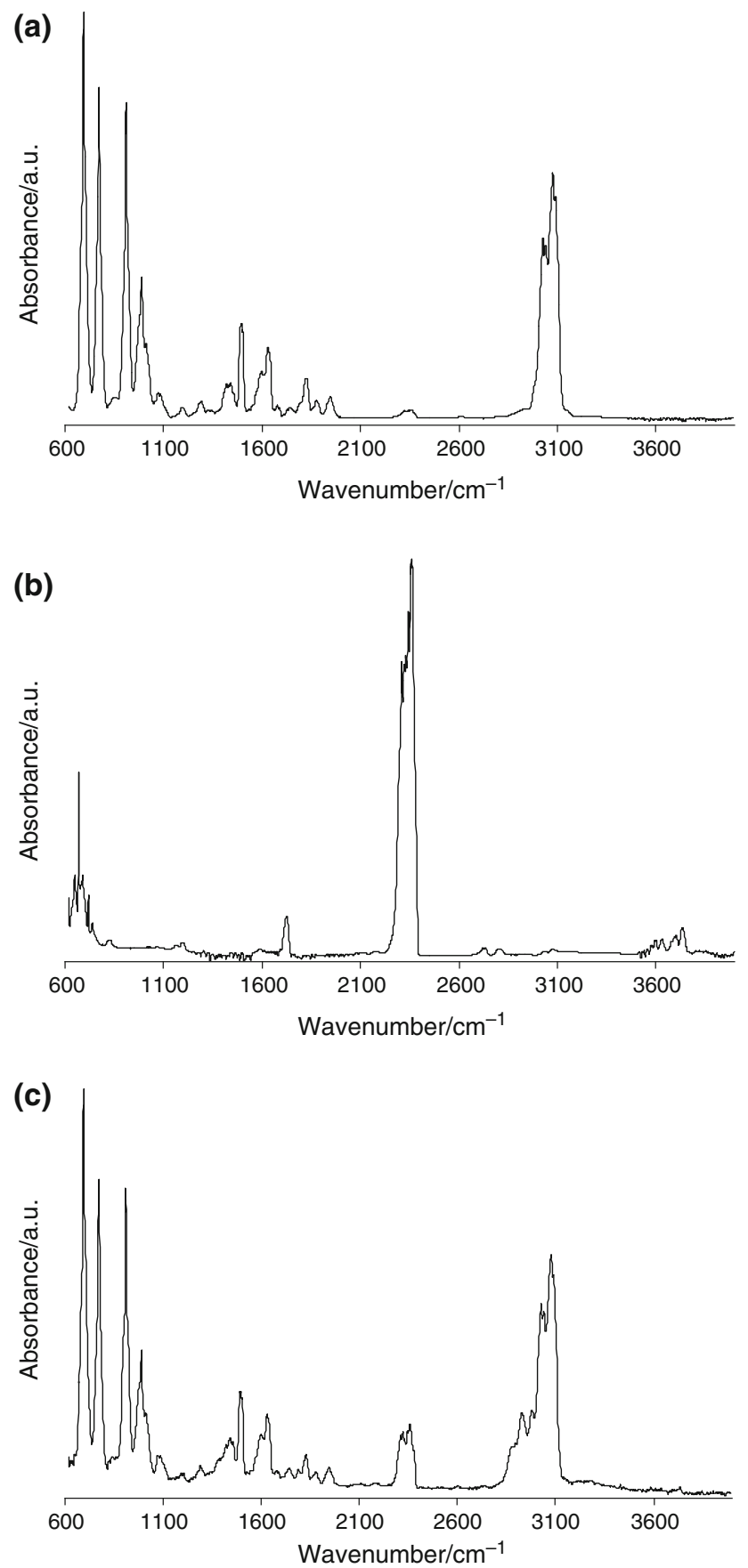

Fig. 3 FTIR spectra of gaseous products emitted during decomposition of PS a and PS/20 mass \% of CBE gathered at $T_{\max 1} \mathbf{b}$ and $T_{\max 2}$ c in inert atmosphere
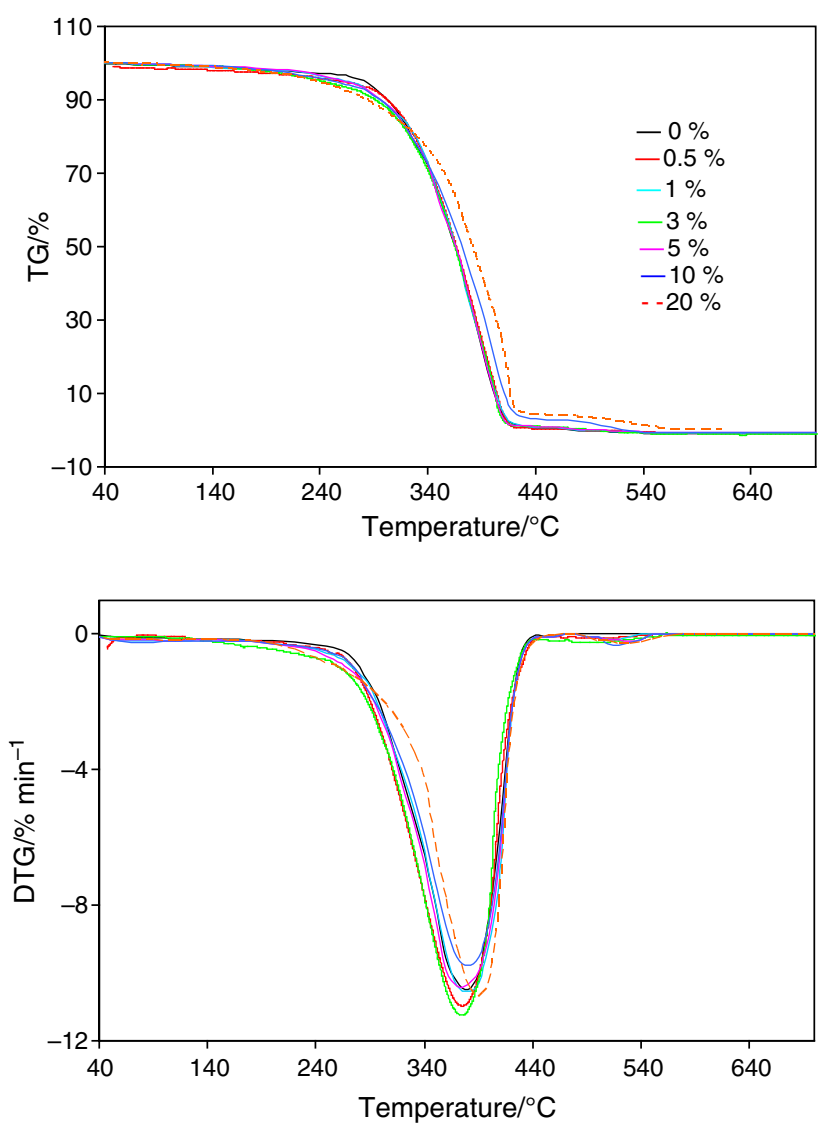

Fig. 4 TG and DTG curves of PS and PS/CBE compositions in oxidative atmosphere

modulus, glass transition temperature and higher values of tg delta height as compared to pure PS and the PS/CBE compositions.

As follows from the data in Tables 3 and 4, increasing the content of ester causes a gradual decrease in the hardness (HK) of the studied compositions. The hardness of pure PS is equal to $143 \mathrm{MPa}$. However, the hardness of the PS/ester compositions is from $130(0.5$ mass $\%)$ to $120 \mathrm{MPa}$ (10 mass\%). The highest drop of hardness values is observed for the PS/20 mass\% ester compositions (98 and $85 \mathrm{MPa}$, respectively). The tensile properties of studied materials are placed in Tables 5 and 6 . The data indicate that the addition of esters to the PS has significant influence on the mechanical properties of prepared compositions. Generally, the PS/esters compositions are characterized by smaller Young modulus and tensile strengths values than pure PS. However, with the increase in the amount of ester in the compositions, the strain at break ultimately increases as well.

Figure 2 presents the TG/DTG curves of obtained materials in inert atmosphere. In addition, the TG/DTG data in inert atmosphere are gathered in Tables 7 and 8. One can 
see that pure PS decomposes in one main stage that is visible from $325^{\circ} \mathrm{C}$ to almost $426{ }^{\circ} \mathrm{C}$ with $T_{\max } 412{ }^{\circ} \mathrm{C}$. Those observations are in accordance with the literature data where $T_{\max }$ of decomposition of PS is contained between 425 and $429^{\circ} \mathrm{C}$ depending on the synthesis and analysis conditions [40-44]. The addition of esters to PS leads to a displacement of the initial decomposition temperature of obtained materials toward lower temperatures. Meanwhile, an increase in the number of the degradation stages is observed together with the presence of esters. The PS/esters compositions decompose in two main stages. The first is appeared at lower temperatures $\left(T_{\max 1}\right)$. The mass loss is from 7.0 to $20.5 \%$ depending on the ester structure and ester content. This decomposition stage is directly connected with the presence of esters in the studied materials. In this temperature range, mainly the emission of gaseous products formed during pyrolysis of esters is expected. As it was already confirmed, the pyrolysis of $\mathrm{CBE}$ and CSE leads to the production of $\mathrm{CO}_{2}, \mathrm{CO}$ and $\mathrm{H}_{2} \mathrm{O}$ as a main gaseous products and small amount of other organic decomposition products such as benzene, toluene, styrene, ethylbenzene, aliphatic, saturated aldehydes or carboxylic acids [32]. The presented FTIR spectrum of the gaseous products emitted at $T_{\max 1}$ confirms this supposition, as shown in Fig. 3. In addition, the evaporation of humidity is expected in this stage. The samples for the TG studies were used in the form of powders and thus the absorption of the humidity from the atmosphere was highly expected. However, one can assume that the second DTG peak observed at $T_{\max 2}$ is due to the decomposition of PS. According to literature survey, the main reaction is the breakage of $\mathrm{C}-\mathrm{C}$ bonds in the main chain of PS under pyrolysis. This step is directly connected with a free-radical chain reaction-depolymerization of PS. It leads to the formation of styrene as a main decomposition product and also some amounts of toluene and ethylbenzene [45-48], as shown in Fig. 3.

The TG/DTG curves of the studied materials under air conditions are presented in Fig. 4. The results show that pure PS decomposes in one main step under oxidative conditions. However, pure PS is characterized by significant lower initial decomposition temperature (IDT) and the temperature of the maximum rate of mass loss $\left(T_{\max 1}\right)$ under air conditions, in Table 9, than under inert conditions, in Table 7. On the contrary, the decomposition of the PS/ester compositions runs as two-stage processes. The first decomposition step is observed at $T_{\max 1} 370-395{ }^{\circ} \mathrm{C}$. The mass loss in this step is from 96 to $99.5 \%$. The second stage occurs at $T_{\max 2}$, in Tables 9 and 10. According to the FTIR spectra gathered at $T_{\max 1}$ and $T_{\max 2}$, Fig. 5 , one can see that $\mathrm{CO}_{2}$ and $\mathrm{H}_{2} \mathrm{O}$ are the main decomposition products of pure PS and PS/ester compositions under air conditions in both stages. It indicates on the thermooxidative degradation of the studied materials $[32,49,50]$.

Table 9 TG and DTG data of PS/CBE compositions in oxidative atmosphere

\begin{tabular}{|c|c|c|c|c|c|c|c|}
\hline CBE content $/ \%$ & First mass loss $/ \%$ & $\mathrm{IDT}_{1} /{ }^{\circ} \mathrm{C}$ & $T_{\max 1}{ }^{\circ} \mathrm{C}$ & $\mathrm{FDT}_{1} /{ }^{\circ} \mathrm{C}$ & Second mass loss $/ \%$ & $T_{\max 2} /{ }^{\circ} \mathrm{C}$ & $\mathrm{FDT}_{2} /{ }^{\circ} \mathrm{C}$ \\
\hline 0 & 100 & 280 & 380 & 450 & - & - & - \\
\hline 0.5 & 99.2 & 260 & 375 & 414 & 0.8 & 475 & 563 \\
\hline 1.0 & 99.3 & 258 & 380 & 414 & 0.7 & 500 & 555 \\
\hline 3.0 & 99.2 & 245 & 375 & 413 & 0.8 & 490 & 560 \\
\hline 5.0 & 99.1 & 245 & 370 & 415 & 0.9 & 530 & 558 \\
\hline 10.0 & 97.4 & 240 & 380 & 418 & 2.6 & 510 & 560 \\
\hline 20.0 & 96.0 & 232 & 395 & 428 & 4.0 & 532 & 587 \\
\hline
\end{tabular}

$I D T$ initial decomposition temperature (express as the temperature where $5 \%$ of mass loss is observed); FDT final decomposition temperature

Table 10 TG and DTG data of PS/CSE compositions in oxidative atmosphere

\begin{tabular}{|c|c|c|c|c|c|c|c|}
\hline CSE content $/ \%$ & First mass loss/\% & $\mathrm{IDT}_{1} /{ }^{\circ} \mathrm{C}$ & $T_{\max 1} /{ }^{\circ} \mathrm{C}$ & $\mathrm{FDT}_{1} /{ }^{\circ} \mathrm{C}$ & Second mass loss $/ \%$ & $T_{\max 2} /{ }^{\circ} \mathrm{C}$ & $\mathrm{FDT}_{2} /{ }^{\circ} \mathrm{C}$ \\
\hline 0 & 100 & 280 & 380 & 450 & - & - & - \\
\hline 0.5 & 99.5 & 260 & 375 & 418 & 0.5 & 480 & 565 \\
\hline 1.0 & 99.0 & 255 & 380 & 417 & 1.0 & 490 & 560 \\
\hline 3.0 & 99.0 & 245 & 380 & 415 & 1.0 & 490 & 560 \\
\hline 5.0 & 99.4 & 240 & 375 & 415 & 0.6 & 520 & 565 \\
\hline 10.0 & 98.2 & 238 & 385 & 420 & 1.8 & 515 & 565 \\
\hline 20.0 & 96.5 & 230 & 390 & 425 & 3.5 & 535 & 590 \\
\hline
\end{tabular}

IDT initial decomposition temperature (express as the temperature where $5 \%$ of mass loss is observed); FDT final decomposition temperature 

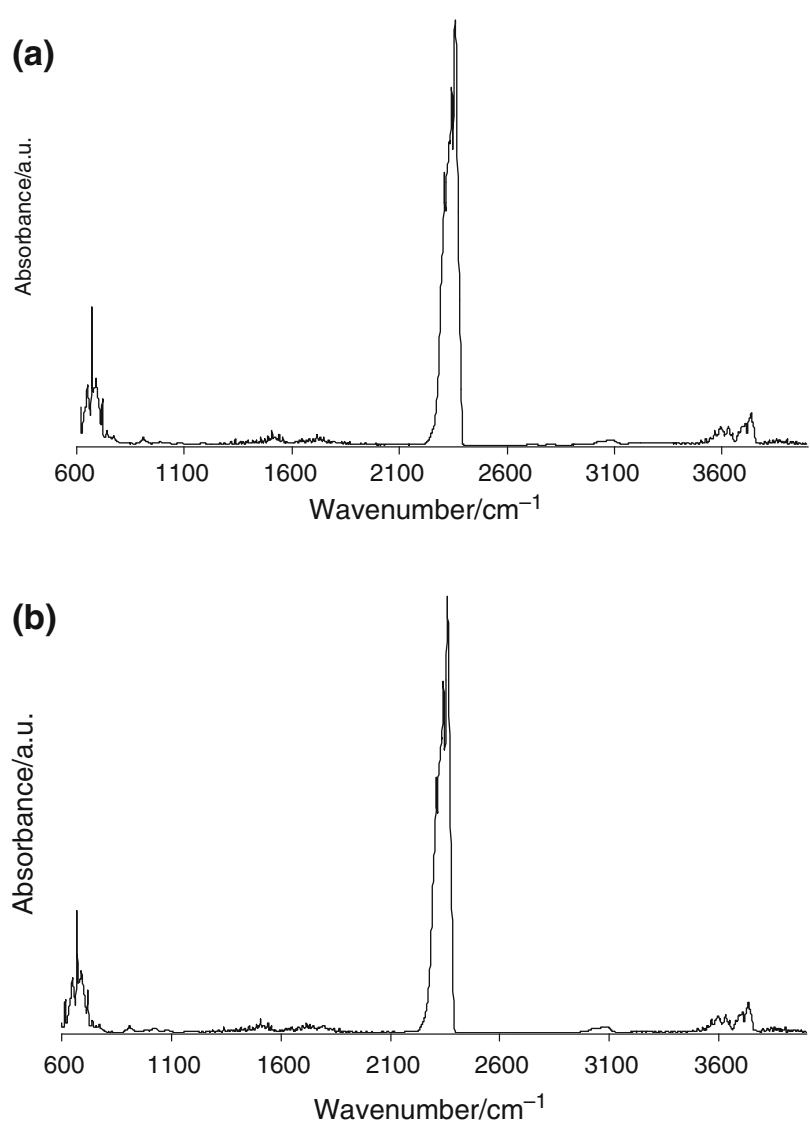

(c)

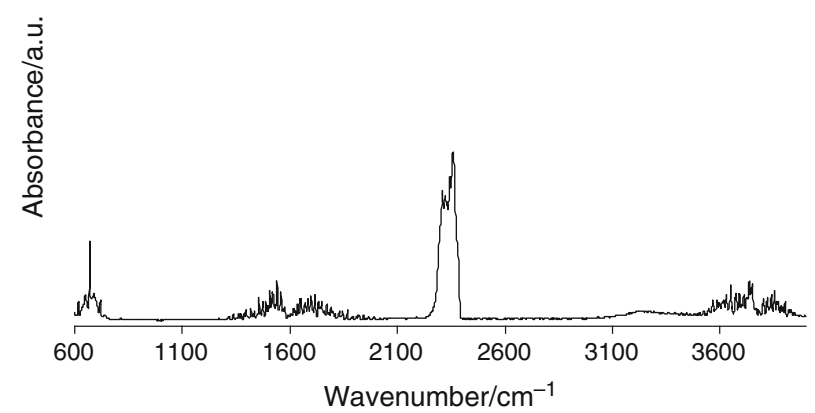

Fig. 5 FTIR spectra of gaseous products emitted during decomposition of PS a and PS/20 mass $\%$ of CBE gathered at $T_{\max 1} \mathbf{b}$ and $T_{\max 2}$ $\mathbf{c}$ in oxidative atmosphere

\section{Conclusions}

The presented results confirmed that the addition of esters derivatives of 3-phenylprop-2-en-1-ol to PS allowed obtaining softer and more flexible materials due to the disruption or weakness of secondary valence bonds between polymer molecules. As a consequence, PS/ester compositions were characterized by lower values of glass transition temperature, storage modulus, Young modulus, stress at break, hardness, thermal stability and higher values of tg delta height and strain at break as compared to pure PS. In addition, it was found that CSE had higher influence on the decreasing the intermolecular interactions and thus the increasing the mobility of the polymer chains of PS than CBE. The studies proved that esters derivatives of 3-phenylprop-2-en-1-ol can be utilized as external, environmentally friendly plasticizers for commercially used thermoplastic polymers such as PS. They can be suitable alternative to widely, industrially applied compounds such as toxic phthalates.

Open Access This article is distributed under the terms of the Creative Commons Attribution License which permits any use, distribution, and reproduction in any medium, provided the original author(s) and the source are credited.

\section{References}

1. Arvanitoyannis I, Biliaderis CG. Physical properties of polyolplasticized edible blends made of methyl cellulose and soluble starch. Carbohydr Polym. 1999;38:47-58.

2. Robertson GL. Food packing: principles and practice. New York: Marcel Dekker; 1993.

3. Wünsch JR. Polystyrene-synthesis, production and applications. UK: Rapra Technology Ltd.; 2000.

4. De Santa Maria LC, Aguiar MRMP, Guimarães IC, Amorim MCV, Costa MAS, Almeida RSM, Oliveira AJB. Synthesis of crosslinked resin based on methacrylamide, styrene and divinylbenzene obtained from polymerization in aqueous suspension. Europ Polym J. 2003;39:291-6.

5. De Santa Maria LC, Aguiar MRMP, D'Elia PD, Ferreira LO, Wang SH. The incorporation of polar monomers in copolymers based on styrene and divinylbenzene obtained from glycerol suspension polymerization. Mater Lett. 2007;61(1):160-4.

6. Xiang K, Wang X, Huang G, Zheng J, Huang J, Li G. Thermal ageing behavior of styrene-butadiene random copolymer: a study on the ageing mechanism and relaxation properties. Polymer Degrad Stab. 2012;9:1704-15.

7. Munteanu BS, Brebu M, Vasile C. Thermal behaviour of binary and ternary copolymers containing acrylonitrile. Polymer Degrad Stab. 2013;98:1889-97.

8. Schnabel W, Levchik GF, Wilkie CA, Jiang DD, Levchik SV. Thermal degradation of polystyrene, poly(1,4-butadiene) and copolymers of styrene and 1,4-butadiene irradiated under air or argon with ${ }^{60}$ Co- $\gamma$-rays. Polymer Degrad Stab. 1999;63:365-75.

9. Sargent M, Koenig JL, Maecker NL. FT-IR analysis of the photooxidation of styrene -acrylonitrile copolymers. Polymer Degrad Stab. 1993;39:355-66.

10. Hung ChY, Hsieh SJ, Wang ChCh, Chen CY. Structural characterization and thermal behavior of dendritic-linear PGMAHPAM-r-PS copolymers in a self-assembled microporous matrix. Polymer Degrad Stab. 2013;98:1196-204.

11. Zhang GZ, Zhang J, Li HJ, Wang J, Zhao S. Synthesis and thermal behavior of gem-dinitro valerylated polystyrene. J Therm Anal Calorim. 2014;117:867-73.

12. Xiang K, Wang X, Huang G, Zheng J, Huang J, Li G. Thermogravimetric studies of styrene-butadiene rubber (SBR) after accelerated thermal aging. J Therm Anal Calorim. 2014;115:247-54. 
13. Erol I, Özcan L, Yurdaka S. Synthesis, characterization, thermal and optical properties of styrene derivatives having pendant $p$ substituted benzylic ether groups. J Therm Anal Calorim. 2013;114:377-85.

14. Rybiński P, Janowska G, Jóźwiak M, Jóźwiak M. Thermal stability and flammability of styrene-butadiene rubber (SBR) composites. J Therm Anal Calorim. 2013;113:43-52.

15. Sears JK, Darby JR. The technology of plasticizers. New York: Wiley; 1982.

16. Godwin AD. In Applied polymer science 21st Century, 9, In: Craver CD, Carraher CE (eds) Elsevier: Oxford 2000.

17. Adelia FFM, Mariana AS, Vieira MGA, Marisa MB. Epoxidation of modified natural plasticizer obtained from rice fatty acids and application on polyvinylchloride films. J Appl Polym Sci. 2013;127:3543-9.

18. Mills A, Lepre A, Wild L. Effect of plasticizer-polymer compatibility on the response characteristics of optical thin $\mathrm{CO}_{2}$ and $\mathrm{O}_{2}$ sensing films. Anal Chim Acta. 1998;362:193-202.

19. Nicolai T, Brown W. Cooperative diffusion of concentrated polymer solutions: a static and dynamic light scattering study of polystyrene in DOP. Macromolecules. 1996;29:1698-704.

20. Schausberger A, Ahrer IV. On the time-concentration superposition of the linear viscoelastic properties of plasticized polystyrene melts using the free volume concept. Macromol Chem Phys. 1995;196:2161-72.

21. Etchenique R, Weisz AD. Simultaneous determination of the mechanical moduli and mass of thin layers using nonadditive quartz crystal acoustic impedance analysis. J Appl Phys. 1999;86:1994.

22. Usui H, Kim JH, Choi DH, Kimura Y, Motoyoshi K. Volume reducing agents for expanded polystyrene, methods and apparatus for processing expanded polystyrene using the same. US Patent 6,403,661, 11 June 2002.

23. Gardner JH. Polybutenes a versatile modifier for plastics, Addcon World '99. In: Conference proceeding, RAPRA Technol. Ltd. Prague, 27th-19th Oct1999, paper 8, p 4.

24. Yang M, Park MS, Lee HS. Endocrine disrupting chemicals: human exposure and health risks. J Environ Sci Health Part C. 2006;24:183-224.

25. Heudorf U, Mersh-Sundermann V, Angerer E. Phthalates: toxicology and exposure. Int J Hyg Environ Health. 2007;210:623-34.

26. Gupta AP, Ahmad S, Dev A. Modification of novel bio-based resin-epoxidized soybean oil by conventional epoxy resin. 2011;51:1087-91.

27. Lee KW, Hailan C, Yinhua J, Kim YW, Chung KW. Modification of soybean oil for intermediates by epoxidation, alcoholysis and amidation. Korean J Chem Eng. 2008;25:474-82.

28. Klinger M, Tolbod LP, Ogilby PR. Influence of a novel castroloil-derived additive on the mechanical properties and oxygen diffusivity of polystyrene. J Appl Polym Sci. 2010;118:1643-50.

29. Quintana R, Persenaire O, Lemmouchi Y, Sampson J, Martin S, Bonnaud L, Dubois P. Enhancement of cellulose acetate degradation under accelerated weathering by plasticization with ecofriendly plasticizers. Polym Degrad Stab. 2013;98:1556-62.

30. Plasticizers: phthalate alternatives. Plast Addit Comp 2002; 4:30-31.
31. Gildemeister E, Hoffmann FR. The volatile oils. New York: Wiley; 1913.

32. Worzakowska M, Ścigalski P. Thermal behavior of cinnamyl diesters studied by the TG/FTIR/QMS in inert atmosphere. J Anal Appl Pyrol. 2014;106:48-56.

33. Rieger J. The glass transition temperature of polystyrene. J Therm Anal. 1996;46:965-72.

34. Olson BG, Peng ZL, McGervey JD, Jamieson AM, Manias E, Giannelis EP. Free volume in layered organosilicate-polystyrene nanocomposites. Mater Sci Forum. 1997;255-257:336-40.

35. Grassie N, Scott G. Polymer degradation and stabilisation. Cambridge: Cambridge University Press; 1985.

36. Madorsky SL. Thermal degradation of organic polymers. New York: Interscience Publishers; 1964.

37. Schnabel W. Polymer degradation: principles and practical applications. New York: Macmillan; 1981.

38. Thermal analysis of polymers. Encyclopedia of polymer science and technology, Wiley; 2005. p 53.

39. Grassie N, Murry EJ, Holmes PA. The thermal degradation of poly(-(D)- $\beta$-hydroxybutyric acid): part 2 -changes in molecular weight. Polym Degrad Stab. 1984;6:95-103.

40. Nair KCM, Thomas S, Groeninckx G. Thermal and dynamic mechanical analysis of polystyrene composites reinforced with short sisal fibres. Compos Sci Technol. 2001;61(16):2519-29.

41. Rana AK, Mitra BC, Banerjee AN. Short jute fiber-reinforced polypropylene composites: dynamic mechanical study. J Appl Polym Sci. 1999;71:531-9.

42. Calvo S, Escribano J, Prolongo MG, Masegosa RM, Salom C. Thermomechanical properties of cured isophtalic polyester resin modified with poly( $\varepsilon$-caprolactone). J Therm Anal Calorim. 2011;103:195-203.

43. Wunderlich B. Thermal analysis. Boston: Academic Press; 1990.

44. Değirmenci L, Durusay T. Thermal degradation kinetics of gőynűk oil shale with polystyrene. J Therm Anal Calorim. 2005;79:663-8.

45. Howell BA. The utilization of TG/GC/MS in the establishment of the mechanism of poly(styrene) degradation. J Therm Anal Calorim. 2007;89:393-8.

46. Poutsma ML. Mechanistic analysis and thermochemical kinetic simulation of the pathways for volatile product formation from pyrolysis of polystyrene, especially for the dimer. Polym Degrad Stab. 2006;91:2979-3009.

47. Audisio G, Bertini F. Molecular weight and pyrolysis products distribution of polymers I Polystyrene. J Anal Pyrol. 1992;24:61-74.

48. Kim JS, Lee W, Lee SB, Kim SB, Choi MJ. Degradation of polystyrene waste over base promoted Fe catalysts. Catal Today. 2003;87:59-68.

49. Peterson JD, Vyazovkin S, Wight CA. Kinetics of the thermal and thermo-oxidative degradation of polystyrene, polyethylene and poly(propylene). Macromol Chem Phys. 2001;202:775-84.

50. Worzakowska M, Torres-Garcia E. Thermo-oxidative kinetic study of cinnamyl diesters. Thermochim Acta. 2015. doi:10.1016/ j.tca.2015.01.014. 